\title{
Development of Shallow Viscous Oil Reserves in North Slope
}

ID Number: DE-FC26-01BC15186

Quarterly Progress Report

Reporting Period Start Date: 1-1-2003

Reporting Period End Date: 3-31-2003

Submitted to the

U.S. Department of Energy

Kishore K. Mohanty

Department of Chemical Engineering

University of Houston

4800 Calhoun Road

Houston, Texas 77204-4004

July, 2003 


\section{Disclaimer}

This report was prepared as an account of work sponsored by an agency of the United States Government. Neither the United States Government nor any agency thereof, nor any of their employees, makes any warranty, express or implied, or assumes any legal liability or responsibility for the accuracy, completeness, or usefulness of any information, apparatus, or process disclosed, or represents that its use would not infringe privately owned rights. Reference herein to any specific commercial product, process, or service by trade name, trademark, manufacturer, or otherwise does not necessarily constitute or imply its endorsement, recommendation, or favoring by the United States Government or any agency thereof. The views and opinions of authors expressed herein do not necessarily state or reflect those of the United States Government or any agency thereof. 


\begin{abstract}
North Slope of Alaska has huge oil deposits in heavy oil reservoirs such as Ugnu, West Sak and Shrader Bluff etc. The viscosity of the last two reservoir oils vary from $\sim 30 \mathrm{cp}$ to $\sim 3000$ cp and the amount in the range of 10-20 billion barrels. High oil viscosity and low formation strength impose problems to high recovery and well productivity. Water-alternate-gas injection processes can be effective for the lower viscosity end of these deposits in West Sak and Shrader Bluff. Several gas streams are available in the North Slope containing NGL and $\mathrm{CO}_{2}$ (a greenhouse gas). The goal of this research is to develop tools to find optimum solvent, injection schedule and well-architecture for a WAG process in North Slope shallow sand viscous oil reservoirs. In the last quarter, we have developed streamline generation and convection subroutines for miscible gas injection. The WAG injection algorithms are being developed. We formulated a four-phase relative permeability model based on two-phase relative permeabilities. The new relative permeability formulations are being incorporated into the simulator. Wettabilities and relative permeabilities are being measured. Plans for the next quarter includes modeling of WAG injection in streamline based simulation, relative permeability studies with cores, incorporation of complex well-architecture.
\end{abstract}




\section{TABLE OF CONTENTS}

Page

Cover Page 1

Disclaimer 2

$\begin{array}{ll}\text { Abstract } & 3\end{array}$

Table of Contents 4

$\begin{array}{ll}\text { Executive Summary } & 6\end{array}$

$\begin{array}{ll}\text { Introduction } & 7\end{array}$

$\begin{array}{ll}\text { Experimental } & 8\end{array}$

Results and Discussion $\quad 11$

$\begin{array}{ll}\text { Technology Transfer } & 21\end{array}$

$\begin{array}{ll}\text { Conclusions } & 21\end{array}$

Plans for Next Reporting Period $\quad 21$

References $\quad 22$ 


\section{List of Graphical Materials}

Page

Fig. 1 Oil saturation from Strator at $0.28 \mathrm{PV}$ injection of $\mathrm{CO}_{2}$ into $\mathrm{C}_{16}$.

Fig. 2 Oil saturation from UTCOMP at $0.28 \mathrm{PV}$ injection of $\mathrm{CO}_{2}$ into $\mathrm{C}_{16}$.

Fig. 3 Oil Saturation at 0.47 PVI.

Fig. 4. Oil saturation from Strator at 0.33 PV of 50-50 injection of PBG and NGL into Shrader oil.

Fig. 5. Oil saturation from UTCOMP at $0.33 \mathrm{PV}$ of 50-50 injection of PBG and NGL into Shrader oil.

Fig. 6. Gas saturation from Strator at 0.33 PV of 50-50 injection of PBG and NGL into Shrader oil.

Fig. 7. Gas saturation from UTCOMP at $0.33 \mathrm{PV}$ of 50-50 injection of PBG and NGL into Shrader oil.

Fig. 8. Second non-aqueous liquid saturation from Strator at $0.33 \mathrm{PV}$ of 50-50 injection of PBG and NGL into Shrader oil.

Fig. 9. Second non-aqueous liquid saturation from UTCOMP at 0.33 PV of 50-50 injection of PBG and NGL into Shrader oil. 16

Fig. 10 Optical and AFM images of adsorbed material on a mica after oil and decalin treatment.

Fig. 11 Optical and AFM images of adsorbed material on a mica after oil and cyclohexane treatment.

Fig. 12 Optical and AFM images of adsorbed material on a mica after oil and toluene treatment. 


\section{Executive Summary}

North Slope of Alaska has huge oil deposits in heavy oil reservoirs such as Ugnu, West Sak and Shrader Bluff etc. The viscosity of the last two reservoir oils vary from $\sim 30 \mathrm{cp}$ to $\sim 3000 \mathrm{cp}$ and the amount in the range of 10-20 billion barrels. High oil viscosity and low formation strength impose problems to high recovery and well productivity. Water-alternate-gas injection processes can be effective for the lower viscosity end of these deposits in West Sak and Shrader Bluff. Several gas streams are available in the North Slope containing NGL and $\mathrm{CO}_{2}$ (a greenhouse gas). The goal of this research is to develop tools to find optimum solvent, injection schedule and well-architecture for a WAG process in North Slope shallow sand viscous oil reservoirs. In the last quarter, we have developed streamline generation and convection subroutines for miscible gas injection. The WAG injection algorithms are being developed. We formulated a four-phase relative permeability model based on two-phase relative permeabilities. The new relative permeability formulations are being incorporated into the simulator. Wettabilities and relative permeabilities are being measured. Plans for the next quarter includes modeling of WAG injection in streamline based simulation, relative permeability studies with cores, incorporation of complex well-architecture. 


\section{Introduction}

North Slope of Alaska has huge oil deposits in heavy oil reservoirs such as Ugnu, West Sak and Shrader Bluff etc (Foerster et al., 1997). These reservoirs overlie existing productive reservoirs such as Kuparak and Milne Point. The viscosity of the West Sak and Shrader Bluff oils vary from $\sim 30 \mathrm{cp}$ to $\sim 3000 \mathrm{cp}$ and the amount is approximately 16 billion barrels. High oil viscosity and low formation strength impose problems to high recovery and well productivity. These challenging reservoirs are the largest undeveloped accumulations in North America. With even modest recoveries, reserves must be considered substantial (a few billion barrels).

Waterflood pilots have been attempted in both West Sak starting in 1984 and Shaeder Bluff in 1991 (Bidinger \& Dillon., 1995). Initial well productivity of approximately 300 BOPD in a 19 API oil is considered low by North Slope standards. The goal of this research is develop the new technology to increase the well productivity as well as the reservoir recovery efficiency. Water-alternate-gas injection processes and modern well architectures can be effective in recovery of the low viscosity $(<100 \mathrm{cp})$ of these deposits in West Sak and Shredder Bluff. Several gas streams are available for the WAG process in the North Slope that contain NGL and $\mathrm{CO}_{2}$. The disposal of (of a few trillion cubic feet of) $\mathrm{CO}_{2}$ will be an added benefit because $\mathrm{CO}_{2}$ is a greenhouse gas and the sequestration of a significant amount of greenhouse gas is a challenge for the mankind in the twenty first century.

This report summarizes our results for the period of January 2003 through March 2003. The five tasks for the project are: (1) Compositional model, (2) Relative permeability, (3) Reservoir simulator, (4) Well Architecture, and (5) WAG optimization. We worked on Tasks 2 and 3 in this quarter; the activities are described in the next section. 


\section{Experimental}

Several North Slope gas streams may be available for injection into shallow sands reservoirs in the North Slope, e.g., Prudhoe NGL, Kuparak NGL, Prudhoe lean gas. Prudhoe gas streams contain a significant amount of $\mathrm{CO}_{2} \cdot \mathrm{CO}_{2}$ cannot be put into potential gas pipelines and is a greenhouse gas. However, mixtures of $\mathrm{CO}_{2}$ and NGL can make effective miscible injectants for shallow viscous reservoirs. The complicating issue in the displacement calculations of these gases is the presence of L1-L2-V phases. Three fluid phases, i.e. a vapor and two liquid phases, have long been observed in hydrocarbon and $\mathrm{CO}_{2}$ mixtures (Meldrum \& Nielsen 1955; Mohanty et al. 1995). Three hydrocarbon phases occurs at relatively low temperatures and pressures. The shallow sands temperature is about $60-100{ }^{\circ} \mathrm{F}$ and pressure about 1200-1800 psi. Thus a compositional simulator is needed that can handle three hydrocarbon phases and water for WAG flood simulations. We have installed a version of UTCOMP, a finite-difference based, threedimensional, equation-of-state compositional simulator (Courtesy: Prof. Gary Pope, University of Texas) which can incorporate three hydrocarbon phases (Chang et al., 1990).

The computational time required for simulation of four phases during WAG floods of 3D reservoirs is prohibitively expensive in traditional finite difference simulators. If large grid blocks are used, then numerical dispersion is large and the results are not accurate. In contrast, streamline method is much faster. Compared with conventional finite difference simulation, streamline simulation is much younger in terms of commercial usage. While finite difference simulation was commercialized in 1960's, the streamline simulation was used in commercial simulators in the 1990's (Osako et al., 2003).

We have developed a streamline simulator (Strator) based on compositional simulation of UTCOMP (Chang, 1990). Strator was developed for waterflood last quarter. It has been confirmed that the streamline method is much faster than conventional finite-difference method. 
Waterflood alone is not effective to be used to recover Shrader viscous oil due to high viscosity of the oil. Slim tube experiments carried out by Mohanty et al. (1992) and Khataniar et al. (1999) showed that solvent flooding was effective because certain solvents were miscible with the viscous oil and thus oil viscosity was reduced. Therefore, in the past three months, Strator was extended for gas injection.

Instead of mapping water saturation from 1D solutions, we map overall compositions of hydrocarbon components for gas injection. The true time step is derived in the next several paragraphs.

At $\mathrm{T}$ (the nth time step), the total cumulative injection of component $\mathrm{i}$ is

$$
N_{i, I}^{n}=N_{i, p}^{n}+N_{i, r}^{n}-N_{i, i n i}
$$

where $N_{i, I}^{n}$ is the total cumulative injection of component $\mathrm{i}$ at the $\mathrm{nth}$ time step, $N_{i, p}^{n}$ the total cumulative production of component $\mathrm{i}$ at the nth time step, $N_{i, i n i}$ is the initial amount of component $\mathrm{i}$, and $N_{i, r}^{n}$ is total amount of component $\mathrm{i}$ still remaining in the reservoir at the $\mathrm{nth}$ time step.

Similarly for the $(n+1)$ st time step, we have

$$
N_{i, I}^{n+1}=N_{i, p}^{n+1}+N_{i, r}^{n+1}-N_{i, i n i}
$$

The total cumulative injection of component $\mathrm{i}$ at the $(\mathrm{n}+1)$ th time step, $N_{i, I}^{n+1}$, can be written as

$$
N_{i, I}^{n+1}=N_{i, I}^{n}+Q_{I}^{n+1} z_{i, I} \Delta T^{n+1}
$$

where $Q_{I}^{n+1}$ is the solvent injection rate at the $(\mathrm{n}+1)$ th time step, $z_{i, I}$ is overall composition of component $\mathrm{i}$ in the solvent, and $\Delta T^{n+1}$ is the true time step at the $(\mathrm{n}+1)$ time step. The total cumulative production of component $\mathrm{i}$ at the $(\mathrm{n}+1)$ th time step, $N_{i, p}^{n+1}$, can be found as 


$$
N_{i, p}^{n+1}=N_{i, p}^{n}+Q_{p}^{n+1} \sum_{j=2}^{4} x_{i, j, p}\left(\frac{f_{j, p}^{n}+f_{j, p}^{n+1}}{2}\right) \Delta T^{n+1},
$$

where $f_{j, p}^{n}$ is the production fractional flow of phase $\mathrm{j}$ at the $\mathrm{nth}$ time step, $f_{j, p}^{n+1}$ is the production fractional flow of phase $\mathrm{j}$ at the $(\mathrm{n}+1)$ th time step, $Q_{p}^{n+1}$ is production rate at the $(\mathrm{n}+1)$ th time step, and $x_{i, j, p}$ is composition of component $\mathrm{i}$ in phase $\mathrm{j}$ in the production fluid. So, from Eqs. 2 to 4, we get

$$
\Delta T^{n+1}=\frac{N_{i, \text { init }}-N_{i, r}^{n+1}+N_{i, I}^{n}-N_{i, P}^{n}}{Q_{I}^{n+1} z_{i, I}-Q_{p}^{n+1} \sum_{j=2}^{4} x_{i, j, p}\left(\frac{f_{j, p}^{n}+f_{j, p}^{n+1}}{2}\right)} .
$$

The true time step is incremented by the above $\Delta T^{\mathrm{n}+1}$ in the $(\mathrm{n}+1)$ st time step.

The two key issues for modeling fluid flow are wettability and four-phase relative permeability. A four-phase relative permeability model has been formulated. This new formulation is being incorporated into the compositional simulator. Adsorption of Shrader Bluff dead oil components on a mica surface has been imaged by an atomic force microscope. Mica is chemically similar to sandstone, but its surfaces are planar. Effect of solvents (cyclohexane, toluene and decalin) has been studied. These solvents are commonly used to clean cores. The mica plates were put in brine solution for a day before aging in viscous oil for three days at $80^{\circ} \mathrm{C}$. The samples were dipped in three different solvents, cyclohexane, toluene and decalin, for a day and dried before probing by tapping mode in air. 


\section{Results and Discussion}

\section{Reservoir Simulation}

After Strator was extended, we used a simple case to test the code. At 700 psi and $69.38^{\circ} \mathrm{F}, \mathrm{CO}_{2}$ was injected into a reservoir with $\mathrm{C}_{16}$. At $0.28 \mathrm{PVI}$, values of oil saturation obtained from Strator and UTCOMP are compared in Figs. 1 and 2, which show that the front generated by using Strator is sharper than that by using UTCOMP. The speed of solvent movement in the diagonal direction predicted by using Strator is faster than its counterpart by using UTCOMP while the results are comparable. Therefore, numerical dispersions from Strator are smaller than those from UTCOMP. Simulations were run by using Strator and 70 by 70 grid blocks for the above case. Oil saturation at 0.47 PVI is shown in Fig. 3, which indicates a lot of viscous fingers. 


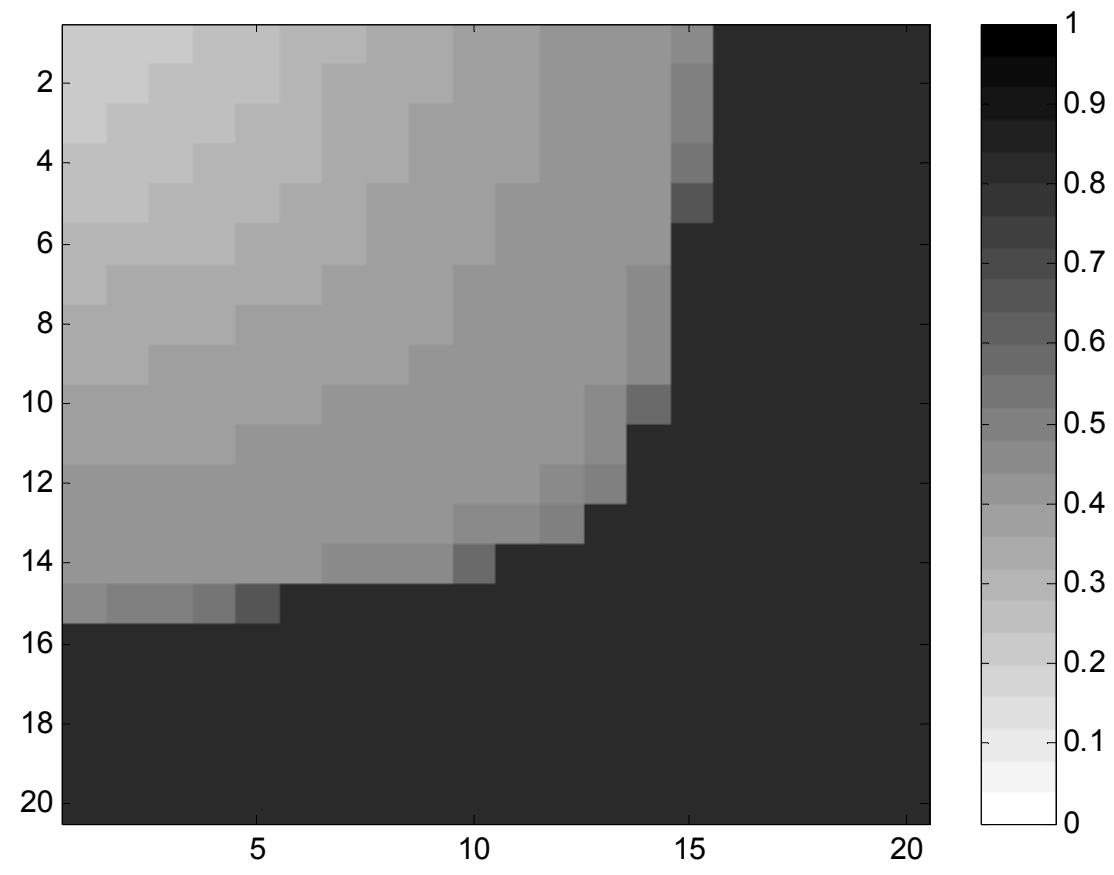

Fig. 1 Oil saturation from Strator at $0.28 \mathrm{PV}$ injection of $\mathrm{CO}_{2}$ into $\mathrm{C}_{16}$.

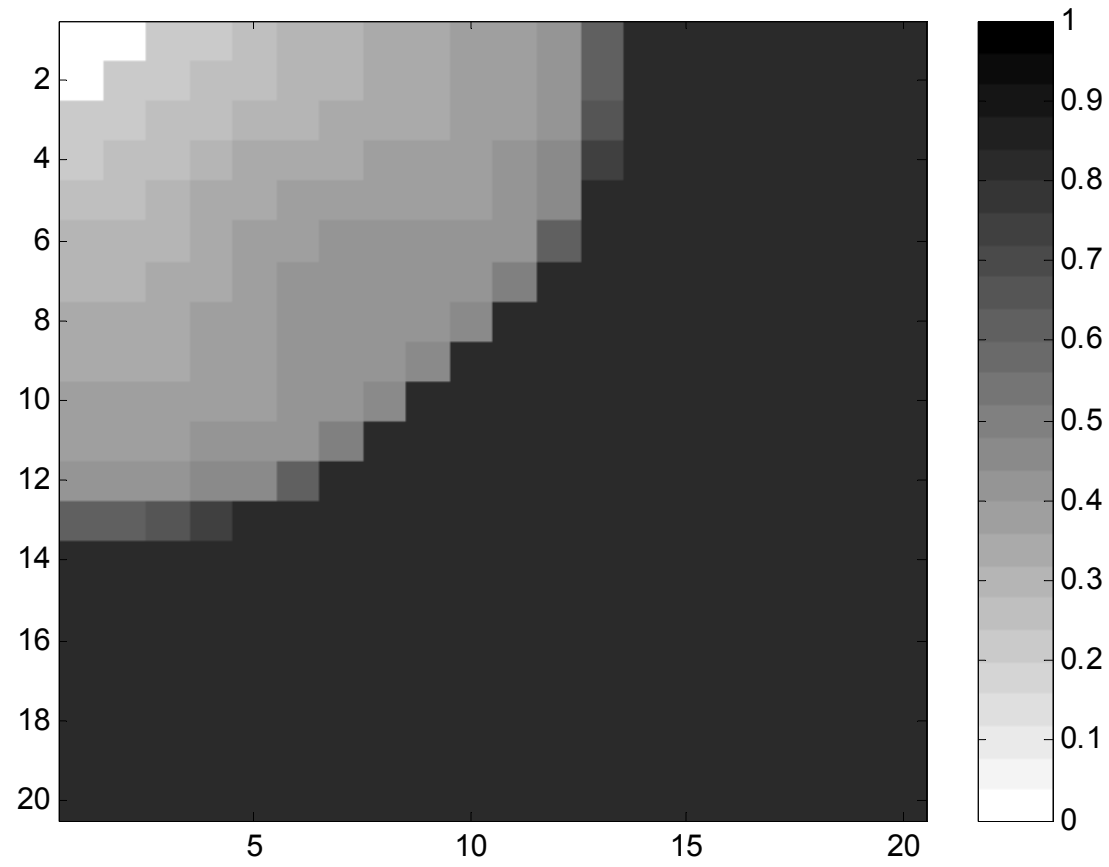

Fig. 2 Oil saturation from UTCOMP at $0.28 \mathrm{PV}$ injection of $\mathrm{CO}_{2}$ into $\mathrm{C}_{16}$. 


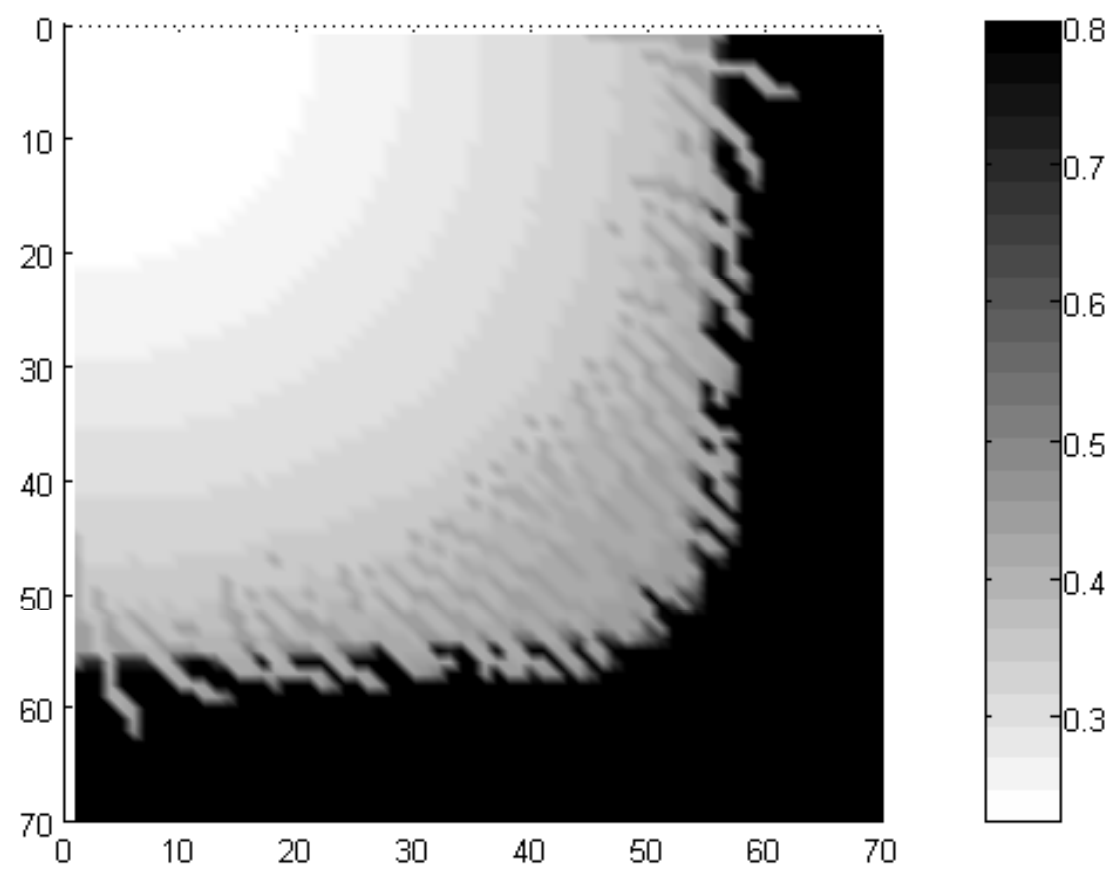

Fig. 3 Oil Saturation at 0.47 PVI

Simulations were run for 50-50 injection of PBG and NGL into a reservoir with Shrader viscous oil. Oil, gas, and second non-aqueous liquid saturations are shown in Figs. 4-9, which indicates that four phases can be simulated by Strator. This simulations show viscous fingering in these gasflood even with $20 \times 20$ grids. These simulations take a 366-MHz Pentium II computer 5 minutes and 21 seconds to run up to $1.2 \mathrm{PV}$ by using Strator and about two hours to run up to 0.6 PV by using UTCOMP. Therefore, the speedup factor is about 43 in this case. 


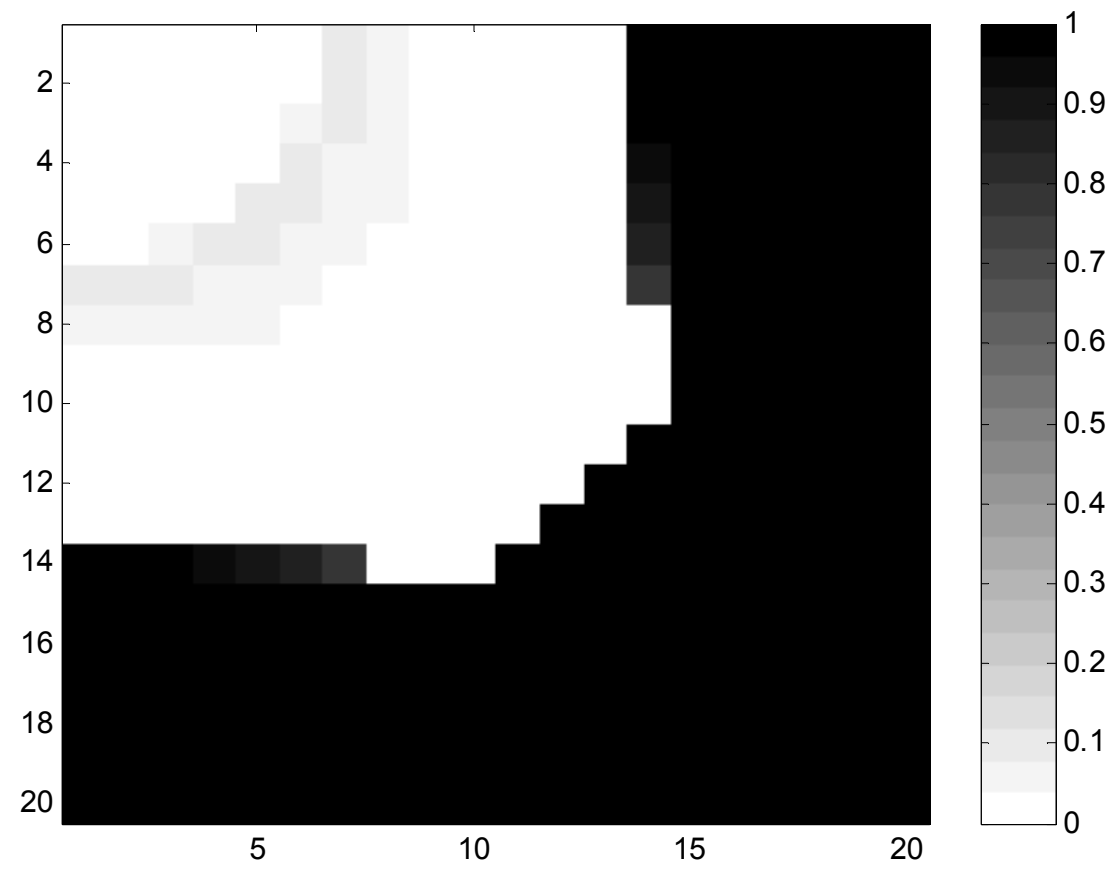

Fig. 4 Oil saturation from Strator at $0.33 \mathrm{PV}$ of 50-50 injection of PBG and NGL into Shrader oil.

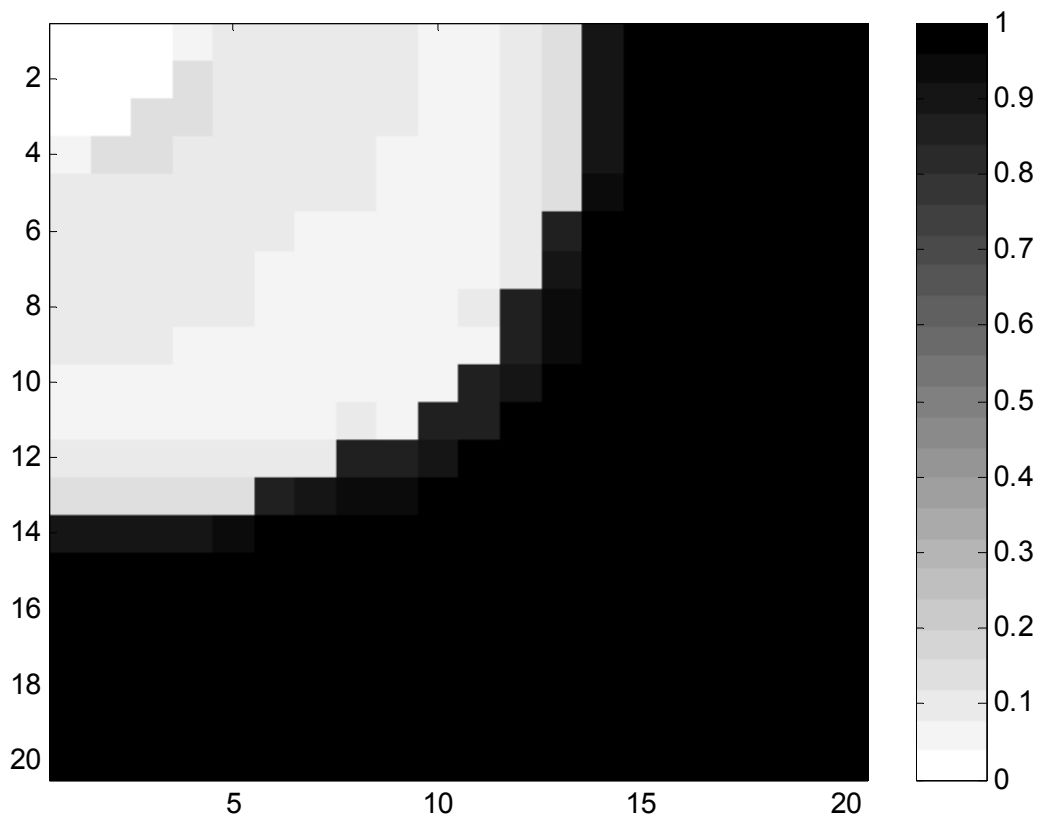

Fig. 5 Oil saturation from UTCOMP at 0.33 PV of 50-50 injection of PBG and NGL into Shrader oil. 

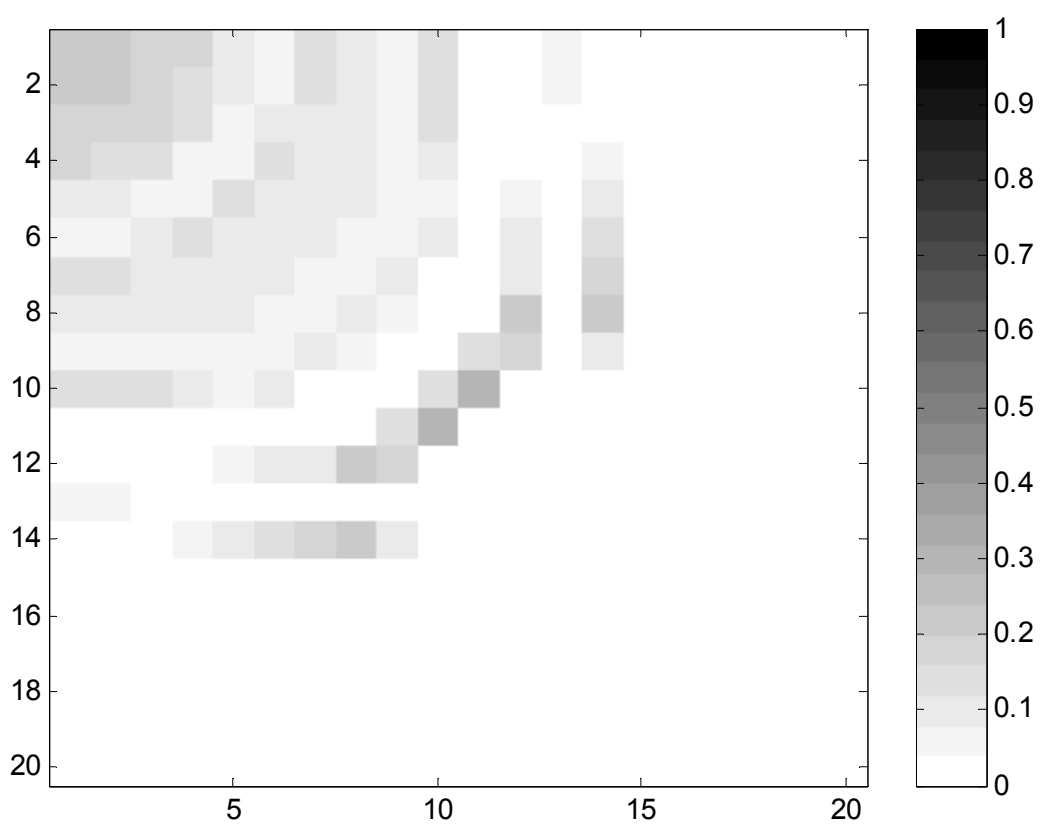

Fig. 6 Gas saturation from Strator at $0.33 \mathrm{PV}$ of 50-50 injection of PBG and NGL into Shrader oil.
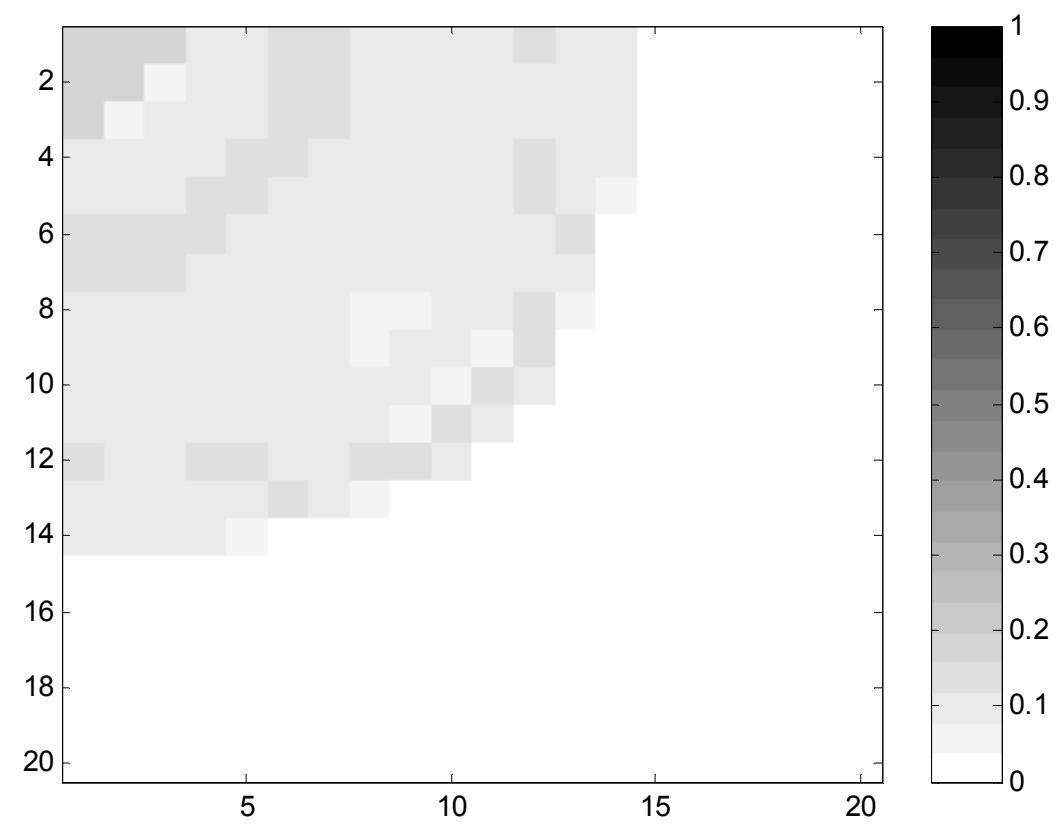

Fig. 7 Gas saturation from UTCOMP at 0.33 PV of 50-50 injection of PBG and NGL into Shrader oil. 


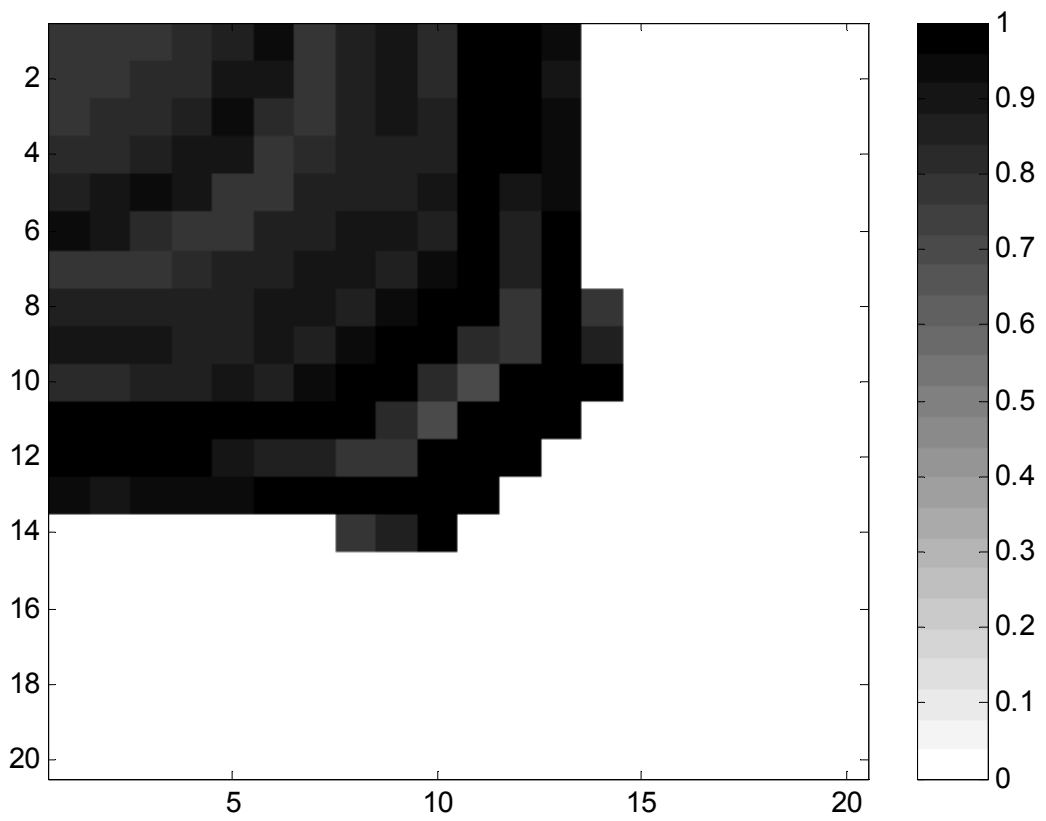

Fig. 8 Second non-aqueous liquid saturation from Strator at $0.33 \mathrm{PV}$ of 50-50 injection of PBG and NGL into Shrader oil.

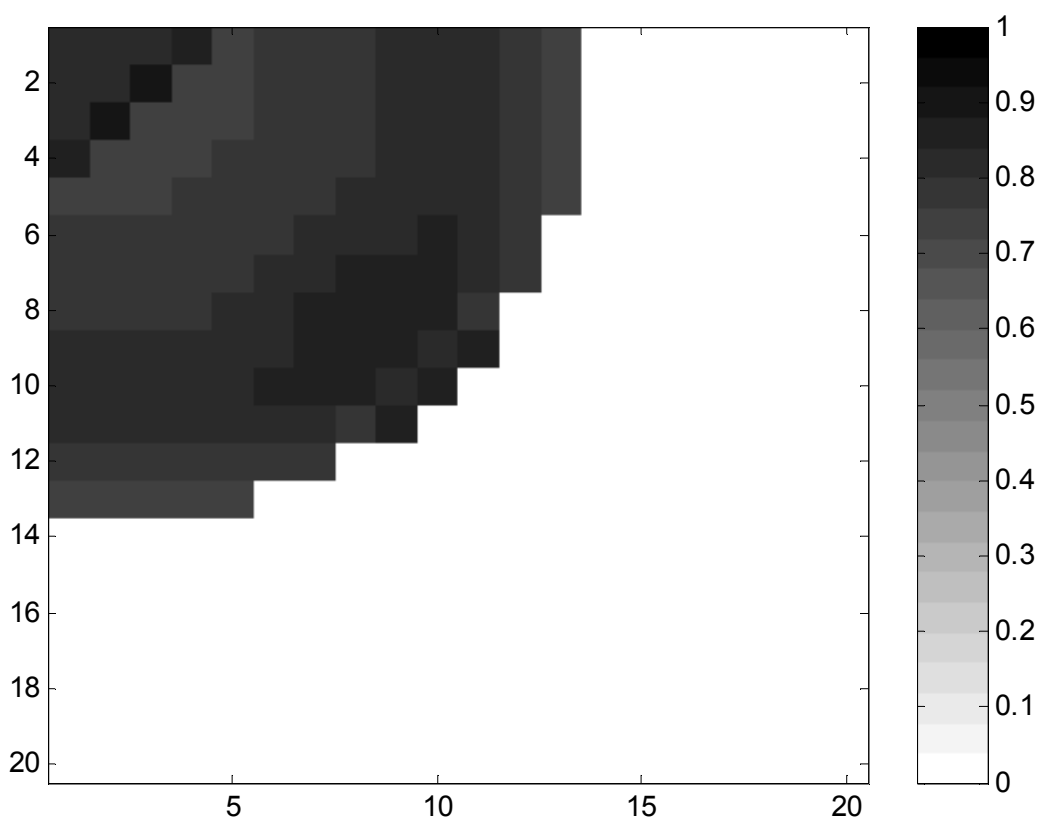

Fig. 9 Second non-aqueous liquid saturation from UTCOMP at $0.33 \mathrm{PV}$ of 50-50 injection of PBG and NGL into Shrader oil. 


\section{Relative Permeability}

1. Decalin-washed Oil-treated mica surface

Fig. 10(a) is an optical image of the decalin-washed mica surface with the size about $200 \mu \mathrm{m}$ x $200 \mu \mathrm{m}$. Fig. 10(b) is a $10 \mu \mathrm{m} \times 10 \mu \mathrm{m}$ height image with a data scale (height) of $50 \mathrm{~nm}$ at the far right. For decalin-washed surfaces, the images show the crude oil component adsorption along preferred lines for both mica and glass (not shown here) surfaces. Fig. 10(c) is the 3-D image of the $10 \mu \mathrm{m} \times 10 \mu \mathrm{m}$ height image shown in Fig. 10(b).

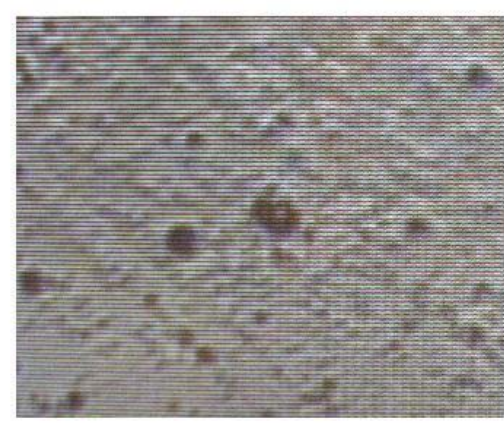

(a)

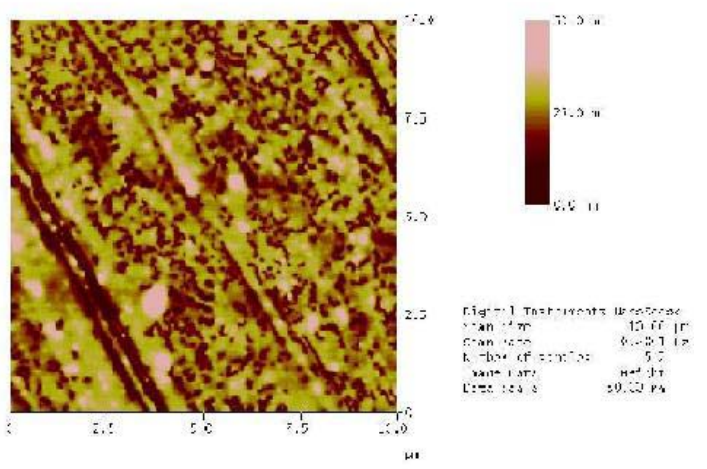

(b)

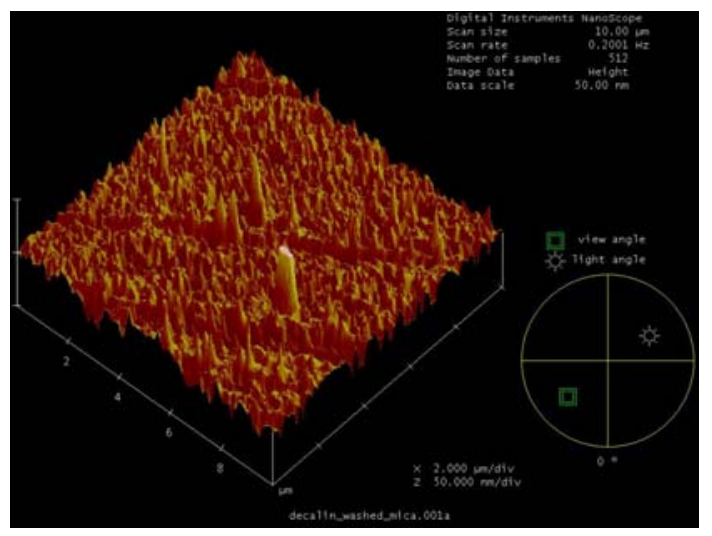

(c)

Fig. 10 Optical and AFM images of adsorbed material on a mica after oil and decalin treatment. 
2. Cyclohexane-washed oil-treated mica surface

Fig. 11(a) is an optical image of the cyclohexane-washed mica surface with the size about 200 $\mu \mathrm{m} \times 200 \mu \mathrm{m}$. Fig. 11(b) is a $100 \mu \mathrm{m} \times 100 \mu \mathrm{m}$ height image with a data scale (height) of 200 $\mathrm{nm}$ at the far right. For cyclohexane-washed mica surface, the $10 \mu \mathrm{m}$ x $10 \mu \mathrm{m}$ scan size image does not show the characteristics of the surface. The oil component adsorption is patchy with a length scale of $\sim 20 \mu \mathrm{m}$. The 3-D image (Fig. 11c) shows a regular distribution of the peaks. The adsorption amount is higher than that of decalin-washed surface.

(a)

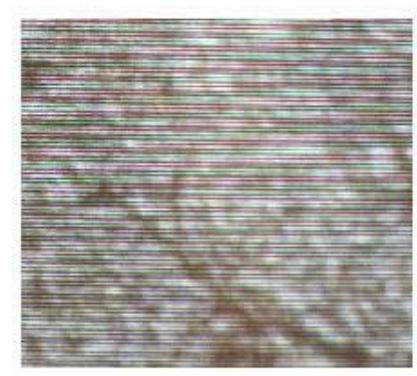

(b)

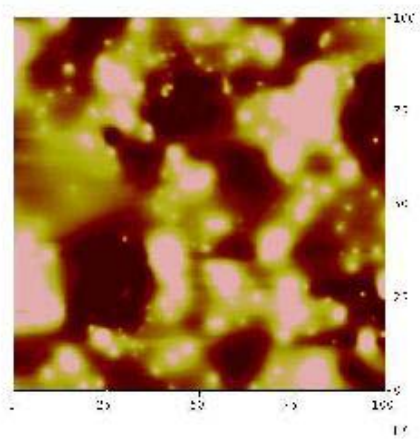

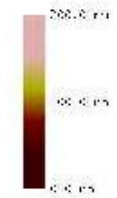

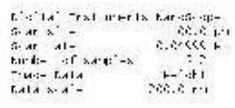

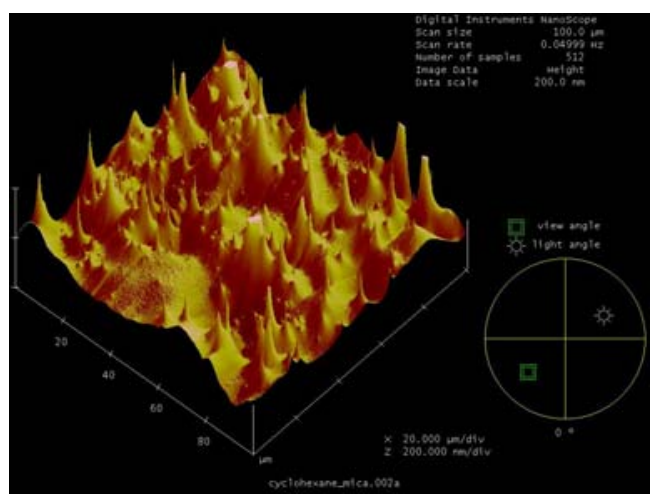

(c)

Fig. 11 Optical and AFM images of adsorbed material on a mica after oil and cyclohexane treatment.

3. Toluene-washed oil-treated mica surface 
Fig. 12(a) below is the optical image of the mica surface after aging with brine, oil and washed with toluene. This image (about $300 \mu \mathrm{m} \times 300 \mu \mathrm{m}$ ) shows the deposition of oil components after washed by toluene. Compared to the image of decalin-washed mica surface, this image shows a denser population of dark spots. Fig. 12(b) below shows a $100 \mu \mathrm{m}$ x $100 \mu \mathrm{m}$ height image of toluene washed mica surface with the data scale of $300 \mathrm{~nm}$. The 3-D image (Fig. 12c) also shows a regular distribution of the peaks. The oil components are adsorbed on patchy region of length scale $\sim 10 \mu \mathrm{m}$.

Toluene and decalin are both aromatic and dissolve asphaltenes better than cyclohexane. When mica is aged with first brine and then oil, some oil components get adsorbed on the solid surface. Washing with solvents removes the bulk oil and perhaps some of the adsorbed components. AFM images show that the amount left behind on the solid surface is the largest in case of cyclohexane, intermediate for toluene and the least for decalin. These components are responsible for making the core surface mixed-wet. 
(a)
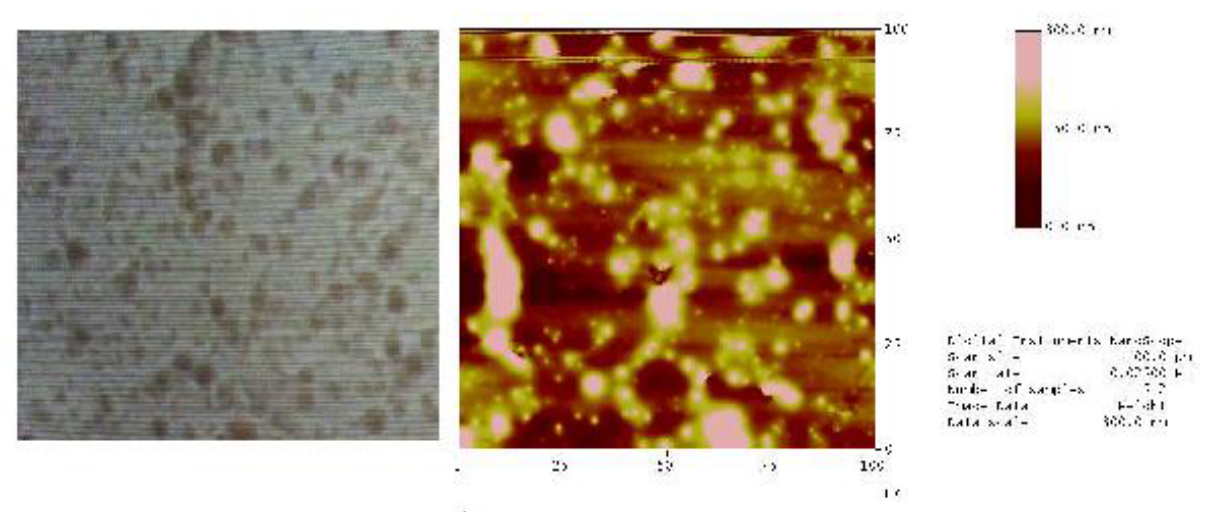

(b)

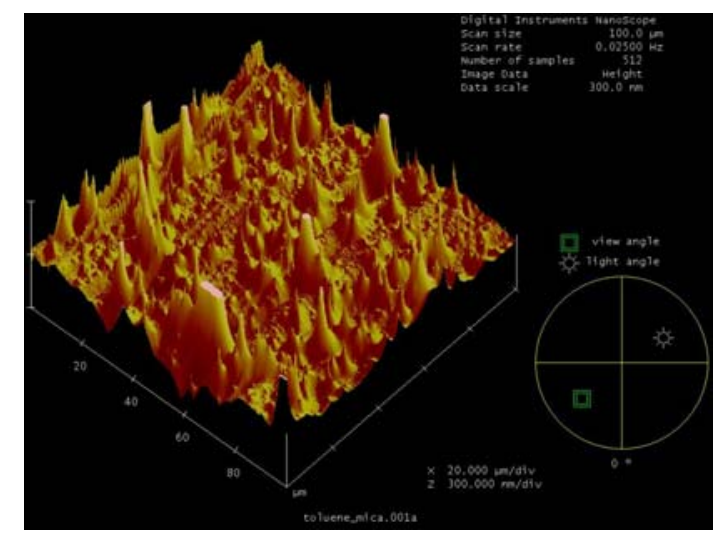

(c)

Fig. 12. Optical and AFM images of adsorbed material on a mica after oil and toluene treatment.

We have completed Amott wettability test for core 1. Core 1 was initially flooded with brine and then flooded with oil with viscosity of $51 \mathrm{cp}$ (diluted dead oil with toluene) to get the primary drainage curve. Aged for 50 days in oil bath, flooded with fresh oil, then flooded with water to get the imbibition curve. The core was then flooded with oil and put in the brine bath (wettability cell) to collect oil. The process was then reversed using oil bath. Another back up core was prepared (core 3). This core was aged in oil for 40 days. This core is now under 
testing for its wettability indices using the Amott wettability cell. Live oil and promising solvent (gas mixtures) are being prepared. Core flood of live oil using solvent at high pressure will be performed in weeks.

\section{Technology Transfer}

We have submitted two abstracts to SPE Fall conference on the basis of this work; they have been accepted.

\section{Conclusions}

- A streamline simulator is being developed for compositional WAG flood. It has been validated for waterflooding and gasflooding (Task 3).

- A four-phase relative permeability model has been formulated. The new formulation is being incorporated into the compositional simulator. Surface force and adsorption of Shrader Bluff dead oil components on a mica surface after washing with three solvents have been imaged by an atomic force microscope. (Task 2).

\section{Plans for Next Reporting Period}

- Evaluate effect of complex well-architecture (Task 4)

- Streamline modeling for WAG flood (Task 3)

- Relative permeability studies with mixed-wet core (Task 2) 


\section{References}

Bidinger, C. R. \& Dillon, J. F., "Milne Point Shrader Bluff: Finding the Keys to Two Billion Barrels," SPE 30289, International Heavy Oil Symposium, Calgary, June 19-21, 1995.

Chang, Y., Pope, G. A. and Sepehrnoori, K., "A Higher Order Finite-Difference Compositional Simulator," J. Petrol. Sc. \& Eng., 5, 35-50, 1990.

Foerester, C. et al., "West Sak Field Development: Analysis of a Marginal Project," SPE 37946, SPE Hyd. Econ. \& Eva., Dallas, March 16-18, 1997.

Khataniar, S., Kamath, V. A., Patil, S. L., Chandra, S. \& Inaganti, M. S., "CO2 and Miscible Gas Injection for Enhanced Recovery of Shraeder Bluff Heavy Oil," SPE 54085, SPE International Thermal Operations and Heavy Oil Symposium, Bakersfield, CA, March 17-19, 1999.

Meldrum, A. H. and Nielsen, R. F., "A Study of Three-Phase Equilibria for Carbon DioxideHydrocarbon Mixtures," Producers Monthly, August 1955, 22-35.

Mohanty, K. et al., "Role of Three-Hydrocarbon -Phase Flow in a Gas Displacement Process," SPE Reservoir Engineering, 214-221, August 1995.

Osako, I., Datta-Gupta, A., and King, M.J., "Timestep Selection during Streamline Simulation via Transverse Flux Correction. Paper SPE 79688 to be presented at the 2003 SPE Reservoir Simulation Symposium to be held in Houston, Feb. 3-5 (2003). 